\title{
A MODEL DRIVEN OPTIMIZATION APPROACH TO DETERMINE TILT ANGLE OF SOLAR COLLECTOR IN INDIA
}

\author{
Sanjaya Kumar Sahu, Nagendra Tripathi and Supriya Tripathi \\ Department of Electrical Engineering \\ Bhilai Institute of Technology, Drug, Chhattisgarh, India
}

\begin{abstract}
The solar systems are an intense need to full fill the energy requirement of developing countries like India. Where, thermal and photovoltaic are the two methods to utilize the solar energy directly from sun. In these methods solar equipments (e.g. flat plat collector and Photovoltaic panel) are kept in tilted position for absorbing maximum solar flux. Hence, finding the optimum tilt angle is the problem of optimization. Therefore, in this paper model driven optimization approach such as particle swarm optimization (PSO) estimator has been proposed to find optimum tilt angle and its results are compared with analytical results. A novel cost function has been applied to determine periodical optimum tilt angle. To validate the performance of PSO estimator results, statistical analysis study is carried out. Where, three statistical approaches such as descriptive method, direct method and Altman-Bland methods are adopted. The PSO estimator results are found satisfactory to ANA results at $95 \%$ confidence interval under statistical study.
\end{abstract}

Keywords: Solar panel, PSO, Bland-Altman, Solar Power

Cite this Article: Sanjaya Kumar Sahu, Nagendra Tripathi and Supriya Tripathi, A Model Driven Optimization Approach to Determine Tilt Angle of Solar Collector in India, International Journal of Advanced Research in Engineering and Technology, 10(2), 2019, pp. 431-448.

http://iaeme.com/Home/issue/IJARET?Volume $=10 \&$ Issue $=2$

\section{INTRODUCTION}

India is in deep energy crisis owing to rising prices of conventional energy sources as well as their scarcity. On other hand, the uses of conventional sources of power generations are not only pollute the environment but also fragile the ecological balance. Thus, there is an urgent need to use environment friendly and renewable energy sources such as solar, wind, geothermal etc. Where, solar energy is most valuable, clean and safe source of energy gifted by the nature.

Owing to its location between the tropic of Cancer and the Equator, India has an average annual temperature that ranges from $25^{\circ} \mathrm{C}$ to $-27.5^{\circ} \mathrm{C}$. On the other hand, being a tropical country, India has huge potential for solar power generation. 
The thermal and photovoltaic conversions are the two methods of direct energy utilization of solar energy. In these two methods most preferable solar equipment's are Flat Plat Collector (FPC) and Photovoltaic Array (PVA) respectively. The solar flux falls on the solar collector depends on the tilt angle from horizontal surface. In other words, the amount of radiation absorbed by solar collector or panels is affected by their orientation and angle of tilt with the horizontal surface. It has been seen that often solar data are given at horizontal surface and also it is not possible to measure the performance of solar equipment's at different tilt angle in large countries like India.

Although, the solar radiation calculation is highly nonlinear, stochastic and site specific, several complex models are available in literature. Further, these models estimate solar radiation in terms of climate parameters such as sunshine hour, relative humidity, cloud layer, maximum temperature etc. [1-3, 7]. The proposed model from different researchers helps to derive the optimum tilt angle at any location around the world from available metrological data on horizontal surface $\beta=0^{\circ}[4-5]$.

In [1] a number of equations related to mean monthly global solar radiant exposure $\left(E_{g}\right)$ available in literature have been reviewed. And it has been observed that the original Angstrom type regression equation which relates $E_{g}$ to clear days radiation at site and average possible sunshine hour ratio are modified by different researchers. These modified models are classified such as linear, polynomial, other (nonlinear, exponential and logarithm term) models. In [7] author has proposed an empirical formula to estimate optimum tilt angle $\left(\beta_{\text {opt }}\right)$, hour angle $(\omega)$ and orientation $(\gamma)$ of solar panel based on generic surface with respect to position of sun. In [811] authors have proposed different empirical formulas to derive optimum tilt angle of solar panel around the world from available metrological data on horizontal surface.

Recently, the soft-computing techniques such as ANN, GA, ANFIS, and PSO etc. becoming popular in solar energy estimation problems of optimization. The ANN to determine $\beta_{\text {opt }}$ has been widely used in solar energy estimation problems [12, 13, and 14]. In [12] the author has taken $E_{g}, \phi, \rho$ and $E_{L}$ as input to ANN model and estimated the optimum tilt angle. Where, Mubiru and Banda [13] have developed ANN based model to predict direct solar irradiance. This proposed ANN model takes sunshine hour, cloud cover, maximum temperature, latitude, longitude as well as altitude of site as input parameters. In [14] author has proposed ANN model to predict direct beam radiation on horizontal surface based on five input parameters such as global solar irradiance, maximum temperature, latitude, longitude and altitude of site. In [15] author has proposed an ANN estimator to predict periodic optimum tilt angle from available input data such as $E_{g(\text { monthly })}, \phi$, and $E_{L}$. Here, ground albedo $(\rho)$ is not taken into account because the variation in $\rho$ is negligible and mostly considered as constant.

The above data driven approach is suitable only if accurate target data to train the ANN is available. But for large country like India due to geographical and astrological variations, accurate and reliable data collection is always not feasible. For reliable data collection it is utmost importance to measure solar radiation data in different part of country. On other hand, the network of radiation measuring stations should be modernized as well as monitored in same data.

In paper [16] GA and Lagrange Multiplier algorithm has been proposed to maximize the photovoltaic panel output. Where, the GA gives initial population at optimal power and then it is feed to Lagrange Multiplier algorithm to find the PV module output power. The [17] presented the $\beta_{\text {opt }}$ calculation for fixed flat solar panel based on Genetic Algorithm (GA) and 
Simulated-Annealing (SA) methods. The relation between sun incident angle and its radiation intensity on solar cell has been presented. The climate data of different location of Taiwan have been used by GA and SA to obtain the optimum tilt angle $\beta_{\text {opt }}$.

Till date no work has been reported to obtain $\beta_{\text {opt }}$ using soft computing (model driven approach) in India. The objective of this work is to propose a model driven approach to determine optimum tilt angle $\left(\beta_{\text {opt }}\right)$ such that total monthly mean daily solar irradiance $\left(E_{g s}\right)$ can be maximized on panel surface. Although the $\beta_{\text {opt }}$ problem can be formulated on daily, weekly, monthly, quarterly, bi-annual and annual basis. In this paper the quarterly, bi-annual and annual model of expected irradiance in $\left(\mathrm{MJ} / \mathrm{m}^{2}\right)$ are presented. The optimum tilt angle of south facing collectors of entire India is calculated on the basis of mean (monthly) global solar irradiance data obtained by Metrological center India [22]. We have proposed a PSO estimator to predict the $\beta_{\text {opt }}$ (periodically). A comparative study of the results obtained by Analytical Analysis (ANA) as well as PSO estimator is carried out. Further, the results of PSO estimators are analyzed based on statistical error tests [17]. In this paper, the results of selected cities of India of different latitude and elevation such as Minicoy (MNC), Thiruvananthapuram (TRV), Port Blair (PBL), Bangalore (BNG), Chennai (CHN) Goa (GOA) Hyderabad (HYD), Visakhapatnam (VSK), Pune (PNE), Mumbai $\quad$ (MMB), Nagpur $\quad$ (NGP), Bhavnagar (BHV), Kolkata (KLK), Ahmadabad (AHM), Bhopal (BHP), Ranchi (RNC), Varanasi (VNS), Shillong (SHL), Patna (PTN), Jodhpur (JDP), Jaipur (JPR), New Delhi (NDL) are presented.

\section{MODELING OF TOTAL SOLAR IRRADIANCE CALCULATOR AT TILTED SURFACE}

In general, sensors are placed in a horizontal position to measure direct solar irradiance at Metrological centers. But in solar energy applications to maximize capture of total solar irradiance the panels are normally kept in tilted position. Hence, it becomes essential to derive total solar radiant exposure from available values of monthly mean of daily/hourly global solar irradiance and monthly mean of daily/hourly diffuse irradiance on the tilted panel surface. Sometimes, global solar irradiation data may either not be available or not be desired form. In such case a typical empirical regression (1) suggested by Gopinathan[3] can be considered when data on sunshine hours are available.

$$
\frac{E_{g}}{E_{g o}}=a_{1}+b_{1}\left(\frac{S}{S_{\max }}\right)
$$

Where, the $a_{1}, b_{1}=f\left\{\phi, E_{L}, S, S_{\max }\right\}$ are regression constants can be obtained by (2-3) [7, 22].

$$
\begin{gathered}
a_{1}=-0.309+0.539 \cos \phi-0.0693 E_{L}+0.290\left(\frac{S}{S_{\max }}\right) \\
b_{1}=1.527+1.027 \cos \phi+0.0926 E_{L}-0.359\left(\frac{S}{S_{\max }}\right)
\end{gathered}
$$

The extraterrestrial solar radiation on a horizontal panel for $d n^{\text {th }}$ day is given as $[7,9$ and 12]

$$
E_{g o}=\frac{24}{\pi} G_{s c}\left(1+0.033 \cos \left(\frac{2 \pi \times d n}{365}\right)\right)
$$


Moreover, to simplify the calculation of $E_{g o}$, Klein has suggested that the extraterrestrial solar radiation in middle of the each month is nearly equal to the monthly mean value [3].The hour angle corresponding to sunrise or sunset on the horizontal surface is given by (5)

$$
\bar{\omega}=\left[\cos ^{-1}(\tan \phi \tan \delta)\right]
$$

Therefore, the corresponding sunshine hour is

$$
\bar{S}=\frac{2}{15}\left[\cos ^{-1}(\tan \phi \tan \delta)\right]
$$

The angle made by the line joining the centers of the sun and earth with the projection of this line on the equatorial plane, is known as declination angle $(\delta)$. There are four models (formulas) are proposed in literature to calculated declination angle, all these formulas are assumption based. All four models are simulated and results are presented in Fig.1.Here could be seen that all four models have no significant difference as far as declination angle calculation is concern.

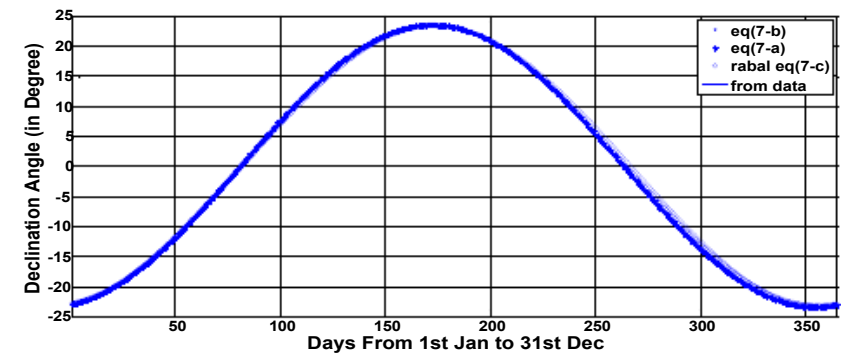

Figure 1 Declination Angle versus day plot

\section{Model-1}

$$
\delta=23.45 \sin \left[\frac{2 \pi(284+d n)}{365}\right]
$$

\section{Model-2}

$$
\delta=\sin ^{-1}\left[\sin (23.45) \times \cos \left(\frac{2 \pi(d n-173)}{365.25}\right)\right]
$$

In equation (7-a) and (7-b) $d n=1$ at $1^{\text {st }}$ Jan of every year [3], [6].

\section{Model-3}

Rble's model of inclination angle [5] is given in equation (7-c)

$$
\delta=\sin ^{-1}\left[-\sin (23.27) \times \cos \left(\frac{2 \pi D}{365.25}\right)\right]
$$

Where D- time after winter solstice (i. e D count starts from 22 DEC onwards)

\section{Model-4}

This is a data driven model for which data is obtained from Indian Metrological Center Pune (Ref Table-7) [22]

The downward solar radiant energy scatted by the suspended particle, air molecules and the clouds. Many researchers have developed empirical for estimating $E_{d} / E_{g}$ ratio for various part 
of world [5, 7, 9, and 22]. In this case the prediction of mean monthly daily diffuse irradiance $\left(E_{d}\right)$ on horizontal surface from ( 8 and 9$)$ is most suitable than other predictors because in fact diffuse components are much larger in India [1-3].

$$
\begin{gathered}
\frac{E_{d}}{E_{g}}=0.8677-0.7365\left(\frac{S}{S_{\max }}\right) \\
\text { or } \frac{E_{d}}{E_{g}}=1.411-1.696\left(\frac{E_{g}}{E_{g o}}\right)
\end{gathered}
$$

\subsection{Solar Irradiance on Tilted Surface}

The total solar irradiance $\mathrm{E}_{\mathrm{gs}}$ on tilted panel is the summation of direct-beam, diffuse and ground reflected radiations on the inclined surface. The $\mathrm{E}_{\mathrm{gs}}$ can be expressed as (10)

$$
E_{g s}=E_{b} \Re_{b}+E_{d} \Re_{d}+E_{g} \Re_{r}
$$

Where,

$$
E_{b}=\left(E_{g}-E_{d}\right)
$$

$\mathfrak{R}_{b}$ for sharp south facing $\gamma=0^{\circ}$ can be expressed as

$$
\begin{gathered}
\mathfrak{R}_{b}=\frac{\omega_{s} \sin \delta \sin (\phi-\beta)+\cos \delta \cos \omega \cos (\phi-\beta)}{\omega_{s} \sin \delta \sin \phi+\cos \delta \cos \omega_{s} \cos \phi} \\
\mathfrak{R}_{d}=(1+\beta) / 2
\end{gathered}
$$

$\mathfrak{R}_{r}$ : If ground reflection to be considered as isotropic [9] then

$$
\Re d=\rho(1-\beta) / 2
$$

$\rho:$ It is the reflection coefficient, generally in India its value in between 0.12 to 0.2 [22].

\section{OPTIMUM TILT ANGLE FORECASTING OF PV PANEL USING PSO ESTIMATOR}

The Particle Swarm Optimization (PSO) is a stochastic optimizationtechnique based on social behaviour of bee swarming or fish schooling. This method has been proven effective fornonderivable objective function as well as its implementationis very easy. In PSO each particle adjust its position in searchspace by its own as well as other particle flying experience tofind the best global solution for each particle. The performanceof each swarm can be improved by defining initial populationrange of each swarm such that each particle closely boundsto the expected domain of feasible region [19], [23]. A realcoded PSO estimator is proposed to find the optimum tiltangle of SOLAR COLLECTOR based on mean monthly global and diffusesolar irradiance during uncertain climate changes at differentlocations in India. The mathematical model of optimizationproblem can be described as follow:

$$
\min \text { or } \max f\left\{X, E_{g s}\right\}
$$

Where, $\mathrm{X}$ is some equality and Non equality constraints and $\mathrm{E}_{\mathrm{gs}}$ is the objective function to be maximize. 


\subsection{Imposed Parametric Constrains}

The imposed parametric constraints in this paper for sharp south facing PV array are as follows:

$$
\begin{gathered}
d n^{\min } \leq d n \leq d n^{\max } \Rightarrow 1 \leq d n \leq 365 \\
\beta^{\min } \leq \beta \leq \beta^{\max } \Rightarrow 0^{\circ} \leq \beta \leq 90^{\circ} \\
\gamma=0^{\circ} ; \text { azimuth angle } \\
\rho=0.2
\end{gathered}
$$

In this work the performance of swarms are made better by putting parametric constraints (lower and upper bound constraints) as shown in (18-21), but linear and nonlinear constraints are not taken into account. In PSOeach particle moves about the cost surface with a velocity. The velocities of particles are controlled by $\omega$ inertia weight. By decreasing $\omega$ global search converges to local search. The particle updates their velocities and position based on the global and local best solution by(22-24). Therefore, the new position of particle can be estimated by following:

$$
\begin{gathered}
v_{n}^{j+1}=\omega v_{n}^{j}+C_{2} r_{1}\left(P_{L B_{n}^{j}}^{j}-P_{n}^{j}\right)+C_{1} r_{2}\left(P_{G B_{n}}^{j}-P_{n}^{j}\right) \\
\omega=\omega^{\max }-\frac{\left(\omega^{\max }-\omega^{\min }\right)}{I_{\text {ter }}^{\max }} \times I_{\text {ter }}
\end{gathered}
$$

Therefore, thenewposition of particle can b e estimatedbyfollowing:

$$
p_{n}^{j+1}=p_{n}^{j}+v_{n}^{j+1}
$$

The [20] demonstrated that the particle swarm is only stable if the following conditions are satisfied:

$$
\begin{aligned}
& \text { Condition-1: } 0<\left(C_{1}+C_{2}\right)<4 \\
& \text { Condition-2: }\left\{\frac{\left(C_{1}+C_{2}\right)}{2}-1\right\}<C_{0}<+1
\end{aligned}
$$

where, $\mathrm{C}_{0}, \mathrm{C}_{1}$ and $\mathrm{C}_{2}$ are inertia, social attraction and cognitive attraction of the particles respectively. Although, the above conditions ensures the convergence of system but that may not be global minimum. By selecting inertia weight tactfully optimal global solution can be achieved in lesser number of iterations. Here, $\omega$ decreases linearly from 0.9 to 0.4 during simulation [19]. The boundary constraint of particle can be managed by either 'Penalize' or 'Reflect' or 'Soft' or 'Absorb' option [20]. In this paper 'Soft' boundary constraint has been taken which sets fitness scores to infinity if particles leave problem bounds. The 'soft' boundary option saves the simulation time since infeasible points are not evaluated.

\subsection{PSO Input Parameters}

The selected input parameters and their imposed parametric constraints areas follows:

$$
\mathrm{X}=\left[\varphi, \mathrm{E}_{\mathrm{L}}, \rho, \mathrm{S}, \mathrm{dn}, \mathrm{E}_{\mathrm{g}}\right]
$$

where, $d n$ is a day of the year $\left(d n=1\right.$ onJan $1^{\text {st }}$ and $d n=365$ onDec $\left.31^{\text {st }}\right)$ and $\rho=0.2$ [22]. 


\subsection{Problem Formulation}

The objective of this work is to maximize the $\mathrm{E}_{\mathrm{gs}}$ over an appropriate period (seasonal, biannual, yearly) by adjusting tilt angle $\beta$ of solar collector of cities of India. Hence, optimum tilt angle ${ }^{\beta_{o p t}}$ can be obtained by maximizing the cost function ${ }^{H_{g s}}\left(\beta_{i}\right)$ calculated from (10) for each city. Therefore, the fitness function to be optimized is obtained by taking harmonic mean of (10) for each of the latitude. The harmonics mean gives largest weight to smallest item and smallest weight to largest item.

$$
F_{\Delta}\left(X_{i}\right)=\left[\frac{\sum_{i=1}^{N / M}\left(\varepsilon_{(\Delta)}\left\{\phi, \beta, \delta, \omega_{s}\right\}+\mu_{(\Delta)}\{\beta\}+\kappa_{(\Delta)}\{\rho, \beta\}\right)^{-1}}{N / M}\right]^{-1}
$$

with, $\Delta=(C \times M) \quad C \in\{1,2, \ldots \ldots . .23\}$ number of cities under study, $\mathrm{N} \in\{12\}$ number of months and $\mathrm{M} \in\{1,2,4\}$ for annual, bi-annual and seasonal period respectively. Here, $\varepsilon_{\Delta}, \kappa_{\Delta}$ and $\mu_{\Delta}$ are the arbitrary functions of corresponding variables.

\subsection{Pseudo-code of PSO Implementation}

The pseudo code to implantation of Particle Swarm Optimization algorithm is as follows:

\section{Begin}

- Select the number of variable to be optimized for each city

- Select number of swarm particles (population size) and generations (maximum no of iterations), as well as $\operatorname{set}_{C_{1}}, C_{2}$ and $\omega_{\min }$ and $\omega_{\max }$ and terminating criteria.

- Impose the parameter constraints (lower bound, upper bound and other constraints if any).

- Randomly initialize the swarm position $\left(p_{n}^{j}\right)$ and velocity $\left(v_{n}^{j}\right)$ of each particle.

\section{Here}

- Randomly generate population.

\section{Next}

- Impose Constraints: Is satisfied?

$>\mathrm{No}$

○ Remove the population and go to next population set.

- Go to: Next

$>$ Yes

- Evaluate fitness function using (25).

- Determine $P_{L B n}^{j}$ and $P_{G B n}^{j}$ for each particle of each city.

- Is terminating Criteria reached?

$>\mathrm{No}$

- Update the swarm position and velocity using (22-24).

- Update the inertia weight.

- Update $P_{L B n}^{j}$ and $P_{G B n}^{j}$ for each particle if its current value is better 


\section{○ Go to :Here}

Yes

○ Compute the best value of $\mathbf{E g s ( m a x )}$ and corresponding independent variable.

End

\section{RESULTS AND DISCUSSION}

In this paper the seasonal, bi-annual and annual optimum tile angles are predicted for selected cities of India using analytical method and PSO estimator. In particular, the solar radiation data of India are considered by taking average on a monthly basis for period of 11 years (1991-2001) from Indian Meteorology Department (IMD) Pune, India [22]. The exhaustive study of 23 cities has been carried out but due to space limitation the results of six selected cities of different latitude are presented in this paper.

\subsection{Comparative study of Analytical and PSO Estimator}

Based on analysis presented in section-II several MATLAB program were developed to calculate the maximum total solar irradiance $E_{\text {gsmax }}$ for $\gamma=0^{\circ}$ using (7-10). The optimum tilt angle was calculated by searching for the value at which maximum $E_{\text {gsmax }}$ will be obtained. The inclination of solar collector may be adjusted to optimum tilt angle hourly, daily and monthly basis. By shortening the adjustment period the total solar irradiance on solar collector can be increased but these adjustments spends lot of manpower or electrical power in automatic tracking system.

Table 1 Optimum Tilt Angle of Solar Collector on Seasonal Basis using Analytical Method and Pso Estimator

\begin{tabular}{|c|c|c|c|c|c|c|}
\hline SNL opt & WN $_{\text {ANA }}$ & AT $_{\text {ANA }}$ & SR $_{\text {ANA }}$ & $\mathbf{W N}_{\text {PSO }}$ & AT \\
PSO & SRPS \\
\hline MNC & 36.00 & 11.00 & 6.00 & 35.51 & 10.65 & 5.70 \\
\hline TRV & 35.00 & 12.00 & 5.00 & 34.63 & 11.86 & 4.89 \\
\hline PBL & 38.00 & 15.00 & 9.00 & 38.33 & 15.06 & 8.83 \\
\hline BNG & 40.00 & 17.00 & 10.00 & 39.82 & 17.08 & 10.23 \\
\hline CHN & 36.00 & 15.00 & 8.00 & 35.82 & 15.03 & 7.87 \\
\hline GOA & 43.00 & 19.00 & 13.00 & 43.41 & 18.65 & 13.11 \\
\hline HYD & 46.00 & 21.00 & 15.00 & 45.74 & 20.65 & 14.59 \\
\hline VSK & 44.00 & 20.00 & 14.00 & 43.57 & 19.61 & 14.48 \\
\hline PNE & 46.00 & 21.00 & 17.00 & 46.35 & 21.40 & 16.93 \\
\hline MMB & 44.00 & 20.00 & 15.00 & 44.07 & 20.29 & 15.06 \\
\hline NGP & 48.00 & 23.00 & 19.00 & 47.72 & 22.73 & 18.76 \\
\hline BHV & 49.00 & 24.00 & 21.00 & 49.45 & 24.02 & 21.29 \\
\hline KLK & 46.00 & 22.00 & 16.00 & 46.11 & 21.73 & 16.49 \\
\hline AHM & 50.00 & 25.00 & 21.00 & 50.07 & 24.96 & 21.34 \\
\hline BHP & 51.00 & 25.00 & 22.00 & 50.55 & 25.13 & 22.29 \\
\hline RNC & 49.00 & 25.00 & 19.00 & 48.97 & 24.73 & 19.08 \\
\hline VNS & 49.00 & 26.00 & 21.00 & 48.93 & 25.74 & 21.19 \\
\hline SHL & 52.00 & 26.00 & 19.00 & 51.85 & 26.23 & 18.91 \\
\hline PTN & 49.00 & 26.00 & 21.00 & 49.46 & 26.16 & 21.43 \\
\hline JDP & 53.00 & 28.00 & 24.00 & 53.40 & 27.78 & 23.95 \\
\hline JPR & 53.00 & 27.00 & 24.00 & 52.60 & 27.22 & 24.26 \\
\hline NDL & 53.00 & 28.00 & 24.00 & 52.71 & 27.93 & 23.79 \\
\hline Note: During summer in all case optimum tilt angle is zero degrees. \\
\hline
\end{tabular}




\subsection{Optimum Tilt Angle on Seasonal Basis}

In this section simulation result for seasonal adjustment of tilt angle of expected total solar irradiance in $\left(\mathrm{MJ} / \mathrm{m}^{2}\right)$ are presented. The Fig. 2 shows the convergence behavior of PSO fitness value for quarter period of the year on seasonal basis. The parameter setting for implementing the proposed PSO algorithm is same as analytical approach. The mean of optimized fitness function reaches to best score 0.0484 at 62 generation. The best individual scores i.e. optimum tilt angle $\left(\beta_{\text {opt }}\right)$ among 62 trails are shown for selected cities of India. The simulation result of ANA and PSO estimator are presented in Table-I, which represents $\beta_{o p t}$ for each season and selected latitude. The total solar irradiance in $\left(\mathrm{MJ} / \mathrm{m}^{2}\right)$ for these approaches to predict the optimum tilt angle is approximately same as shown in Table-2. Form Table-1 and Table-2 it can be observed that PSO approach has better ability to optimize the tilt angle of solar collector to maximize the collection solar energy.

Table 2 Maximum Total Solar Irradiance $E_{g s m a x}\left(\mathrm{Mj} / \mathrm{M}^{2}\right)$ Corresponding to Optimum Tilt Angle of Solar Collector on Seasonal Basis using Analytical Method And Pso Estimator

\begin{tabular}{|c|c|c|c|c|c|c|c|c|}
\hline $\mathrm{EgS}^{\mathrm{SNL}}{ }_{\text {max }}$ & WNANA $_{\text {AN }}$ & $\mathbf{A T}_{\text {ANA }}$ & SM ${ }_{\text {ANA }}$ & SR $_{\text {ANA }}$ & WNPSO & AT PSo & SMP SO & SRPso \\
\hline MNC & 19.83641 & 21.38782 & 16.89667 & 18.03976 & 19.83696 & 21.38811 & 16.89665 & 18.03992 \\
\hline TRV & 93009 & 22.62209 & 18.27667 & 19.27795 & 20.93041 & 2.62214 & 18.27665 & 19.27797 \\
\hline PBL & 0.87194 & 21.56291 & 14.49000 & 15.48524 & 20.8722 & 21.56292 & 14.49000 & 15.48528 \\
\hline $\mathrm{BNG}$ & 22.45604 & 24.39020 & 19.10333 & 17.99929 & 22.45613 & 24.39022 & 19.10332 & 17.99938 \\
\hline $\mathrm{CHN}$ & 18.05185 & 23.34558 & 20.71000 & 18.28982 & 18.05191 & 23.34559 & 20.70991 & 18.28985 \\
\hline GOA & 24.70772 & 24.33953 & 18.36333 & 18.56207 & 24.70823 & 24.33986 & 18.36331 & 18.56209 \\
\hline HYD & 24.76370 & 24.95038 & 20.83333 & 19.08179 & 24.76391 & 24.95074 & 20.83333 & 19.08213 \\
\hline VSK & 8330 & 22.55773 & 18.56333 & 17.35751 & 21.28378 & .55811 & & \\
\hline PNE & 23.00623 & 24.00730 & 20.20000 & 18.39556 & 23.00657 & 24.00775 & 20.19983 & 18.39557 \\
\hline MMB & 20.69352 & 22.88859 & 18.10000 & 16.62857 & 20.69353 & 22.88880 & 18.10000 & 16.62857 \\
\hline NGP & 21.73389 & 23.03411 & & & & 23.0 & & 05 \\
\hline BHV & 24.92165 & 25.46497 & 21.71000 & 19.95153 & 24.9223 & 25.46497 & 21.70998 & 19.95170 \\
\hline KLK & 17.40086 & 19.53731 & 17.63333 & 15.64165 & 17.40089 & 19.53746 & 17.63333 & 15.64200 \\
\hline AHM & 22.91214 & 24.20319 & & & & & & \\
\hline BHP & 23.62239 & 23.90539 & 19.55000 & 18.10153 & 23.62300 & 23.90544 & 19.54999 & 18.10168 \\
\hline $\mathrm{RNC}$ & 21.00614 & 21.73724 & 17.48000 & 15.37815 & 21.00615 & 21.73741 & 17.47995 & 15.37816 \\
\hline VNS & 17.95321 & 21.99334 & 19.85667 & 17.72611 & & 21.99351 & 19.85662 & 17.72617 \\
\hline SHL & 21.50543 & 20.55688 & 16.96333 & 15.20201 & 21.50549 & 20.55700 & 16.96333 & 15.20202 \\
\hline PTN & 18.17297 & 21.91169 & 19.55000 & 17.40627 & 18.17343 & 21.91175 & 19.54998 & 17.40659 \\
\hline JDP & 23.57504 & 23.44017 & & 21.17992 & & 23.44030 & 22.78332 & 21.17992 \\
\hline JPR & 21.74466 & 23.80239 & 22.84333 & 19.67433 & 21.74510 & 23.80251 & 22.84332 & 19.67447 \\
\hline NDL & 19.18953 & 22.26277 & 22.01333 & 18.91019 & 19.18971 & 22.26278 & 22.01333 & 18.91028 \\
\hline
\end{tabular}

\subsection{Optimum Tilt Angle on Bi-annual Basis}

The aim of this section is to predict the optimum tilt angle of solar collector such that by adjusting it twice a year maximum solar irradiance $\mathrm{MJ} / \mathrm{m}^{2}$ can be achieved. The bi-annual tilt angle estimation results of PSO are shown in Fig.3. Presently, the PSO estimator is set for 55 generations but in bi-annual adjustment PSO displayed a premature convergence i.e. mean fitness value reaches to best score in less time. The convergence of bi-annual fitness function reaches to best score with in 37 generations. The bi-annual average of daily solar radiant 
exposure $E_{g s m a x}\left(\mathrm{MJ} / \mathrm{m}^{2}\right)$ for corresponding $\beta_{\text {opt }}$ for different cities is presented in Table-4. Table-3 presents bi-annual optimum tilt angle of solar collector for south direction $\left(\gamma=0^{\circ}\right)$.

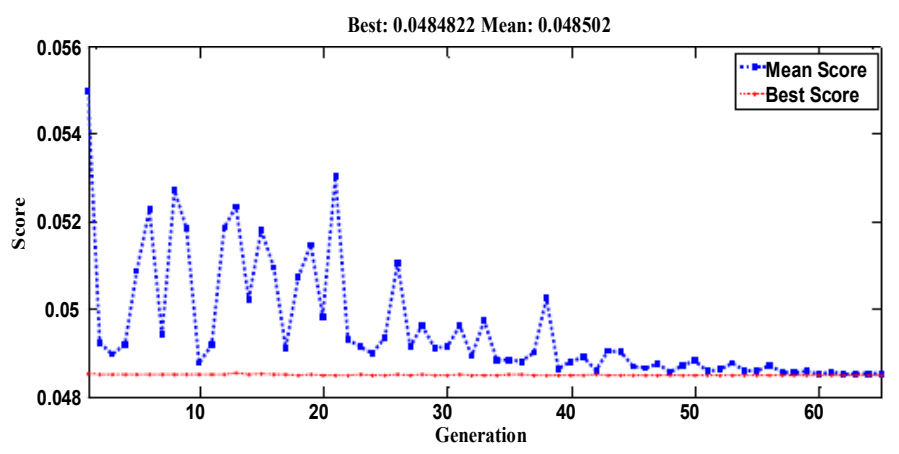

Figure 2 Seasonal Optimum Tilt angle of Selected Cities of India using PSO

\subsection{Optimum Tilt Angle on Annual Basis}

The convergence behaviour of the fitness value of PSO method for annual basis is shown in Fig.4. The best score of PSO fitness function reaches to 0.04344 at 55 generations. The best individual scores (in degree) among 55 trails are shown for selected cities of India. As shown in Table-5 and Table- 6 the proposed PSO approach has better ability to locate the optimum solution then other methods.

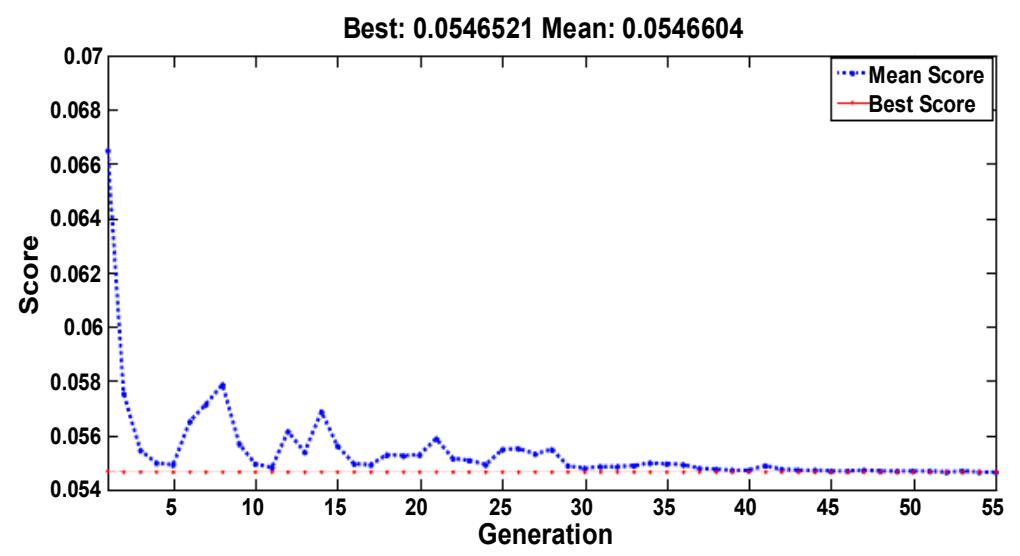

Figure 3 Bi-annual Optimum Tilt angle of Selected Cities of India using PSO

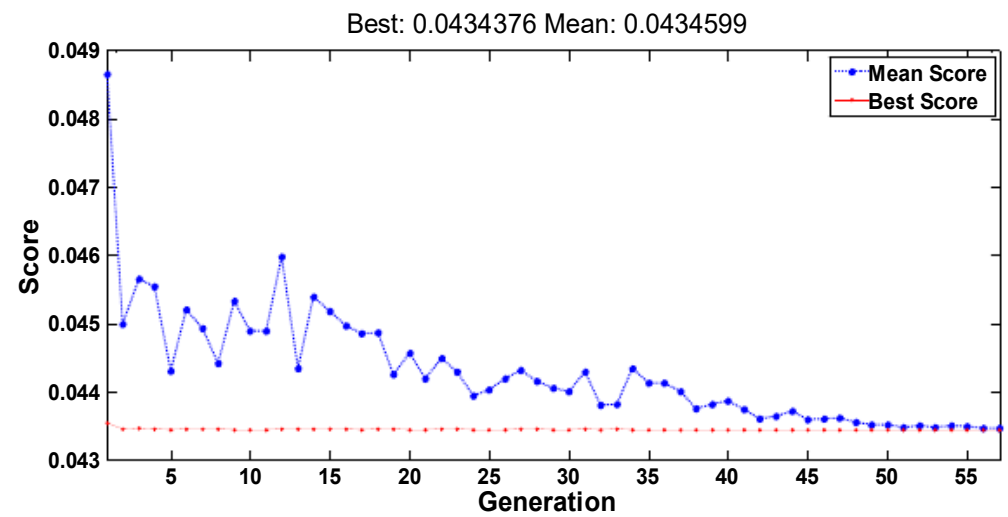

Figure 4 Yearly Optimum Tilt angle of Selected Cities of India using PSO 
A Model Driven Optimization Approach to Determine Tilt Angle of Solar Collector in India

Table 3 Optimum Tilt Angle of Solar Collector on Bi-Annual Basis Using Analytical Method and Pso Estimator

\begin{tabular}{|c|c|c|c|c|}
\hline BYR & COL $_{\text {ANA }}$ & HOT $_{\text {ANA }}$ & COL $_{P S O}$ & HOTP SO \\
\hline MNC & 23.00 & 0.00 & 22.99 & 0.00 \\
\hline TRV & 23.00 & 0.00 & 22.99 & $2.60 \mathrm{E}-03$ \\
\hline PBL & 27.00 & 0.00 & 26.66 & $8.60 \mathrm{E}-02$ \\
\hline BNG & 28.00 & 0.00 & 28.04 & $6.60 \mathrm{E}-05$ \\
\hline CHN & 24.00 & 0.00 & 23.86 & $9.60 \mathrm{E}-04$ \\
\hline GOA & 32.00 & 1.00 & 31.68 & $7.40 \mathrm{E}-01$ \\
\hline HYD & 34.00 & 0.00 & 33.57 & $9.28 \mathrm{E}-04$ \\
\hline VSK & 32.00 & 2.00 & 31.65 & 1.53 \\
\hline PNE & 34.00 & 3.00 & 34.00 & 2.56 \\
\hline MMB & 32.00 & 2.00 & 31.87 & 2.21 \\
\hline NGP & 35.00 & 5.00 & 35.37 & 4.85 \\
\hline BHV & 37.00 & 6.00 & 37.16 & 6.47 \\
\hline KLK & 34.00 & 4.00 & 33.76 & 4.45 \\
\hline AHM & 38.00 & 7.00 & 37.71 & 6.67 \\
\hline BHP & 38.00 & 8.00 & 38.32 & 7.67 \\
\hline RNC & 37.00 & 5.00 & 37.04 & 5.11 \\
\hline VNS & 36.00 & 8.00 & 36.48 & 7.64 \\
\hline SHL & 40.00 & 7.00 & 40.17 & 7.03 \\
\hline PTN & 37.00 & 8.00 & 37.08 & 7.90 \\
\hline JDP & 41.00 & 10.00 & 41.36 & 9.82 \\
\hline JPR & 40.00 & 9.00 & 39.95 & 9.39 \\
\hline NDL & 40.00 & 10.00 & 39.98 & 10.03 \\
\hline
\end{tabular}

\subsection{Statistical Error Analysis}

The statistical methods to assess agreement two quantitative methods such as PSO-ANA of prediction of optimum $\beta$ have been presented. Where, results obtained by PSO estimator have been compared with analytical results. Here, there are three statistical methods have been adopted such as descriptive analysis, direct comparison method and simple graphical (BlandAltman) method. In direct comparison method it could be answered that whether one method of $\beta$ estimation might replace the other with sufficient accuracy. The merits of this approach are that the data will always cluster around a regression line and for comparing two methods it is much more informative. In graphical method difference versus mean of two methods are scattered and it is recommended that $95 \%$ of data points should lie within ( $\pm 2 \mathrm{SD}$ ) of the mean difference. Where, Bland-Altman is a reliably simple graphical parametric approach based on analysis of variance.

Table 4 Maximum Total Solar Irradiance Egsmax $\left(\mathrm{Mj} / \mathrm{M}^{2}\right)$ Corresponding to Optimum Tilt Angle of Solar Collector on Bi-Annualbasis using Analytical Method and Pso Estimator

\begin{tabular}{|c|c|c|c|c|}
\hline Egsmax & COLANA & HOT $_{\mathrm{ANA}}$ & COLPSO $_{\text {PSO }}$ & HOTPSO $_{\text {PSO }}$ \\
\hline MNC & 20.24228 & 17.43833 & 20.25462 & 17.43825 \\
\hline TRV & 21.45145 & 18.75500 & 21.46491 & 18.75496 \\
\hline PBL & 20.87102 & 14.93167 & 20.88790 & 14.93166 \\
\hline BNG & 23.04798 & 18.46333 & 23.06854 & 18.46333 \\
\hline $\mathrm{CHN}$ & 20.44831 & 19.44667 & 20.45985 & 19.44666 \\
\hline GOA & 24.05584 & 18.31425 & 24.08164 & 18.31419 \\
\hline HYD & 24.35346 & 19.75000 & 24.38119 & 19.75000 \\
\hline VSK & 21.54058 & 17.79022 & 21.56152 & 17.79020 \\
\hline PNE & 23.03781 & 19.05433 & 23.06354 & 19.05415 \\
\hline
\end{tabular}


Sanjaya Kumar Sahu, Nagendra Tripathi and Supriya Tripathi

\begin{tabular}{|c|c|c|c|c|}
\hline Egsmax & COLANA & HOT $_{\text {ANA }}$ & COLPSO & HOTPSO \\
\hline MMB & 21.42115 & 17.20370 & 21.44067 & 17.20349 \\
\hline NGP & 21.94672 & 18.07562 & 21.97135 & 18.07501 \\
\hline BHV & 24.66544 & 20.45251 & 24.69699 & 20.45233 \\
\hline KLK & 18.15072 & 16.46724 & 18.16775 & 16.46682 \\
\hline AHM & 23.08033 & 19.31221 & 23.11013 & 19.31158 \\
\hline BHP & 23.26927 & 18.46966 & 23.29900 & 18.46923 \\
\hline RNC & 20.97718 & 16.20159 & 21.00206 & 16.20083 \\
\hline VNS & 19.64620 & 18.48987 & 19.66862 & 18.48869 \\
\hline SHL & 20.59940 & 15.90208 & 20.62798 & 15.90148 \\
\hline PTN & 19.70797 & 18.17986 & 19.73142 & 18.17850 \\
\hline JDP & 23.00606 & 21.52961 & 23.04057 & 21.52764 \\
\hline JPR & 22.30897 & 20.82034 & 22.33835 & 20.81866 \\
\hline NDL & 20.33185 & 20.09996 & 20.35808 & 20.09780 \\
\hline
\end{tabular}

Table 5 Optimum Tilt Angle of Solar Collector on Yearly Basis using Analytical Method and Pso Estimator

\begin{tabular}{|c|c|c|c|c|c|}
\hline$\beta_{\text {opt }}$ & ANA & PSO & $\beta_{\text {opt }}$ & ANA & PSO \\
\hline MNC & 11.00 & 10.51 & BHV & 25.00 & 25.50 \\
\hline TRV & 11.00 & 10.94 & KLK & 22.00 & 21.73 \\
\hline PBL & 17.00 & 16.60 & AHM & 26.00 & 25.83 \\
\hline BNG & 17.00 & 16.57 & BHP & 27.00 & 26.95 \\
\hline CHN & 11.00 & 11.27 & RNC & 25.00 & 25.47 \\
\hline GOA & 21.00 & 20.72 & VNS & 24.00 & 24.24 \\
\hline HYD & 21.00 & 20.74 & SHL & 29.00 & 28.62 \\
\hline VSK & 20.00 & 20.08 & PTN & 25.00 & 24.88 \\
\hline PNE & 22.00 & 22.25 & JDP & 28.00 & 28.11 \\
\hline MMB & 21.00 & 20.94 & JPR & 27.00 & 27.01 \\
\hline NGP & 24.00 & 23.78 & NDL & 27.00 & 26.92 \\
\hline
\end{tabular}

\subsection{Descriptive Methods}

The statistical test results of optimum tilt angle prediction of approaches under study (ANA and PSO) are presented in Table-VII and Table-VIII for annual, bi-annual and seasonal period. Where, it can be observed that there is no significance difference in mean, Standard Deviation (SD) and median of all three methods (ANA and PSO) of $\beta_{\text {opt }}$ prediction of solar collector but this estimation of agreement approach is less effective for larger estimation errors. The covariance and Pearson test result of correlation for two-sided t-test at $95 \%$ confidence interval for annual, bi-annual and seasonal period are given in Table-IX and X. The null hypothesis ( $\left.H_{0}: \rho=0\right)$ is rejected in favor of alternative hypothesis $\left(H_{0}: \rho \neq 0\right)$ at $5 \%$ significance level i.e. there is a significance correlation in PSO-ANA estimator result. Moreover, the correlation between ANA and PSO estimator is high $[0.999(\mathrm{p}<0.001)]$. In this section difference of mean, standard deviation (SD), median and correlation of multivariate analysis are explored to estimate the agreement of two methods. The correlation coefficient $(\rho)$ only measure the relation between methods but it doesn't grantee the agreement between them. The change in scale of measurement/estimation does not affect the correlation unlike agreement. On the other hand some time data shows poor agreement but produces quite high correlation. Therefore, the correlation coefficient is of no use in practice to compare two methods for their agreement [21]. 
A Model Driven Optimization Approach to Determine Tilt Angle of Solar Collector in India

Table 6 Maximum Total Solar Irradiance $\operatorname{Eg} \operatorname{smax}\left(\mathrm{Mj} / \mathrm{M}^{2}\right)$ Corresponding to Optimum Tilt Angle of Solar Collector on Bi-Annual Basis using Analytical Method and Pso Estimator

\begin{tabular}{|c|c|c|c|c|c|}
\hline$\beta_{\text {opt }}$ & ANA & PSO & $\beta_{\text {opt }}$ & ANA & PSO \\
\hline MNC & 18.4607 & 18.4612 & BHV & 22.0373 & 22.0379 \\
\hline TRV & 19.7254 & 19.7254 & KLK & 16.9679 & 16.9680 \\
\hline PBL & 17.5620 & 17.5623 & AHM & 20.6994 & 20.6995 \\
\hline BNG & 20.2919 & 20.2922 & BHP & 20.3931 & 20.3931 \\
\hline CHN & 19.5682 & 19.5683 & RNC & 18.1462 & 18.1466 \\
\hline GOA & 20.7172 & 20.7174 & VNS & 18.6852 & 18.6853 \\
\hline HYD & 21.4251 & 21.4253 & SHL & 17.8010 & 17.8013 \\
\hline VSK & 19.2488 & 19.2488 & PTN & 18.5548 & 18.5548 \\
\hline PNE & 20.5440 & 20.5441 & JDP & 21.7023 & 21.7024 \\
\hline MMB & 18.9284 & 18.9284 & JPR & 21.0576 & 21.0576 \\
\hline NGP & 19.5661 & 19.5662 & NDL & 19.7709 & 19.7709 \\
\hline
\end{tabular}

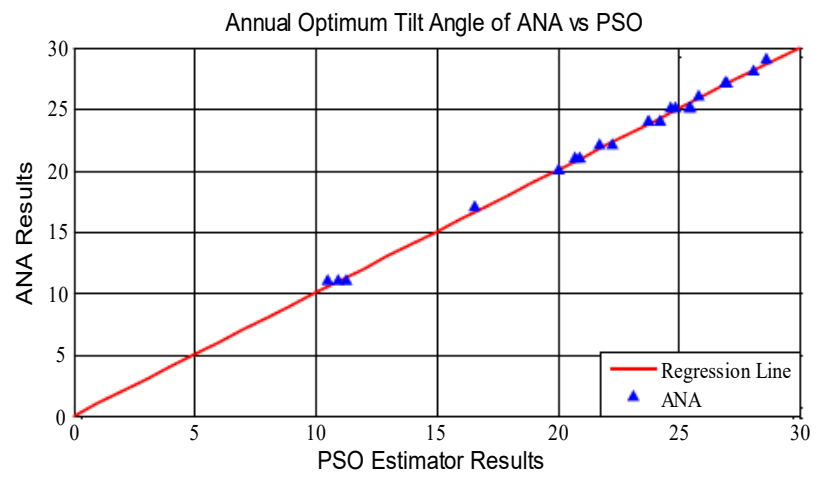

Figure 5 Annual Optimum Tilt angle of ANA versus PSO Estimator Results

\subsection{Direct Comparison Method}

In direct comparison method it could be answered that whether one method of tilt angle estimation might replace the other with sufficient accuracy. Fig.5, Fig.6 and Fig.7 show the scatter plot between ANA-PSO result with line of equality for annual, bi-annual and seasonal period respectively. The merit of this approach is that the data will always cluster around line of regression which is more informative for comparing two methods.
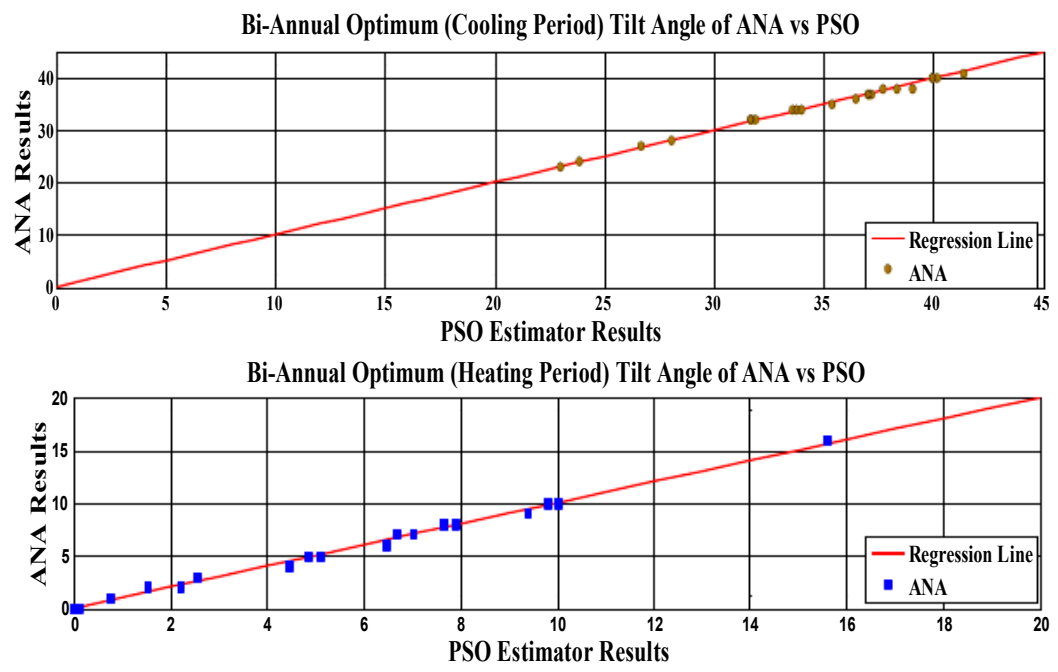

Figure 6 Bi-annual Optimum Tilt angle of ANA versus PSO Estimator Results 
Sanjaya Kumar Sahu, Nagendra Tripathi and Supriya Tripathi
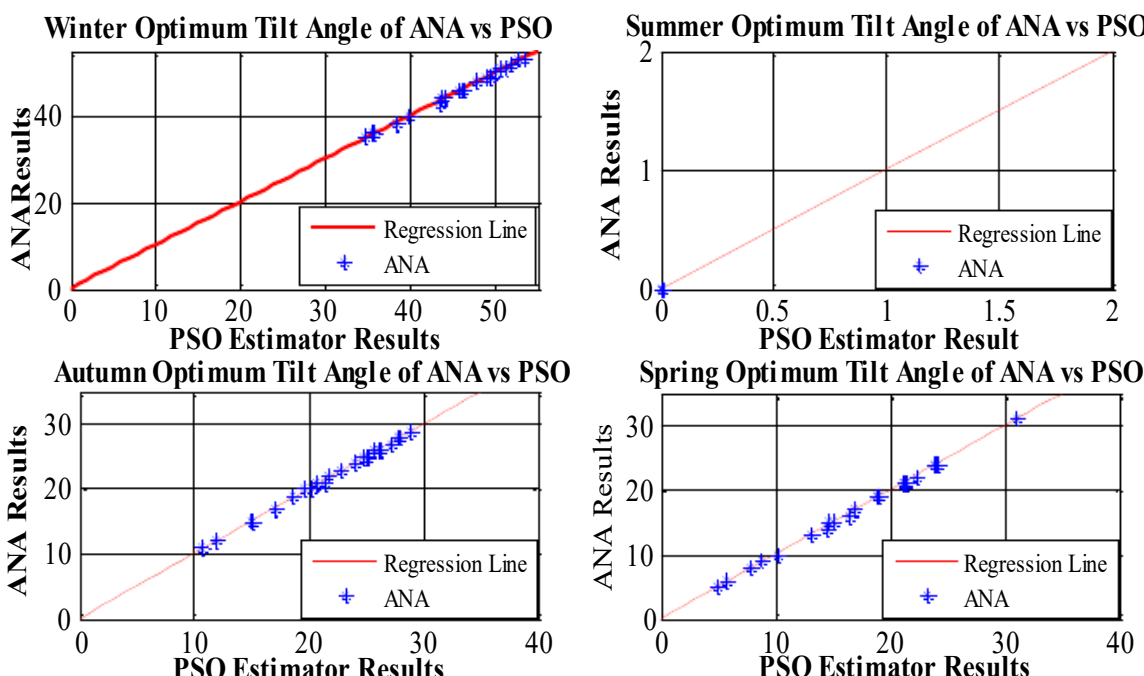

Figure 7 Seasonal Optimum Tilt angle of ANA versus PSO Estimator Results

Table 7 Comparison of Multivariate Analysis Result of Annual $\beta_{\text {opt }}$ Based on Annual Results

\begin{tabular}{|c|c|c|c|c|c|c|}
\hline \multirow{2}{*}{ Parameter } & \multicolumn{2}{|c|}{ ANNUAL } & \multicolumn{2}{c|}{ COL PERIOD } & \multicolumn{2}{c|}{ HOT PERIOD } \\
\cline { 2 - 7 } & ANA & PSO & ANA & PSO & ANA & PSO \\
\hline Mean & 22.0 & 21.9 & 33.9 & 33.9 & 4.8 & 4.8 \\
\hline SD & 5.40 & 5.45 & 5.50 & 5.68 & 4.3 & 4.3 \\
\hline Median & 24.0 & 23.8 & 35.0 & 35.4 & 5.0 & 4.8 \\
\hline
\end{tabular}

Table 8 Comparison of Multivariate Analysis Result of Seasonal $\beta_{\text {opt }}$

\begin{tabular}{|c|c|c|c|c|c|c|}
\hline Parameter & \multicolumn{2}{|c|}{ WINTER } & \multicolumn{2}{c|}{ AUTUMN } & \multicolumn{2}{c|}{ SPRING } \\
\hline & ANA & PSO & ANA & PSO & ANA & PSO \\
\hline Mean & 46.0 & 46.1 & 22.0 & 21.9 & 17.1 & 17.2 \\
\hline SD & 5.7 & 5.8 & 5.2 & 5.2 & 6.5 & 6.6 \\
\hline Median & 48.0 & 47.7 & 23.0 & 22.7 & 19.0 & 18.8 \\
\hline
\end{tabular}

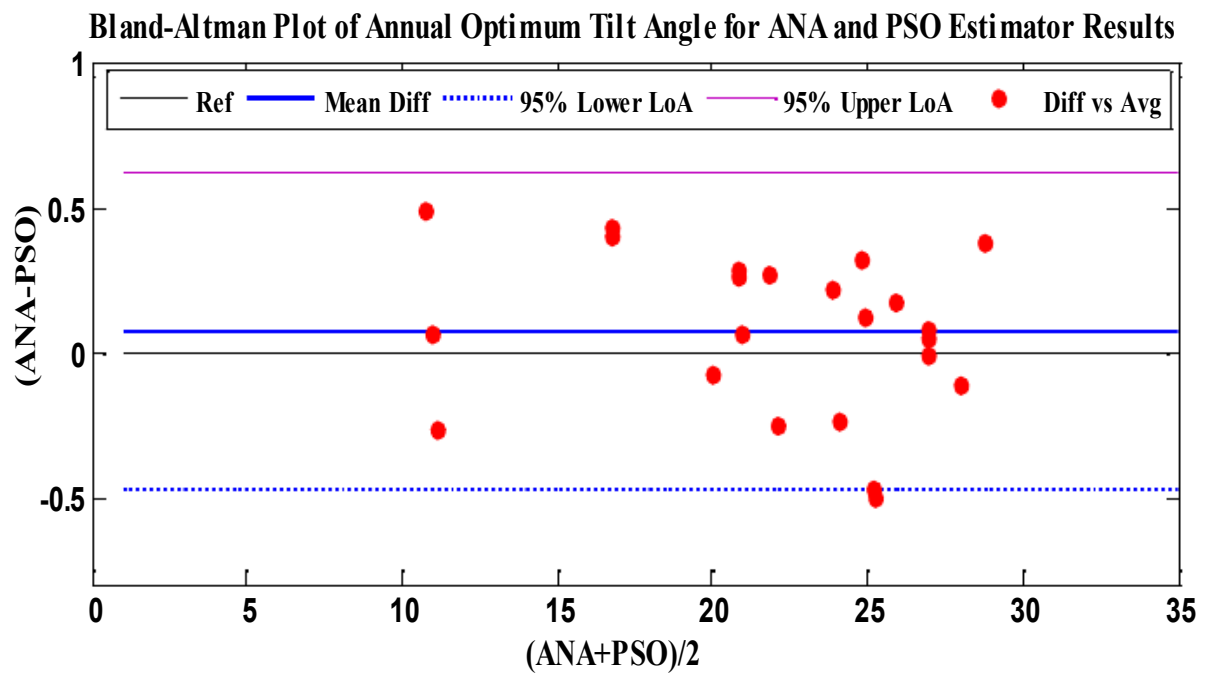

Figure 8 Bland-Altman Plot of Annual Optimum Tilt Angle of ANA versus PSO Estimator Results 

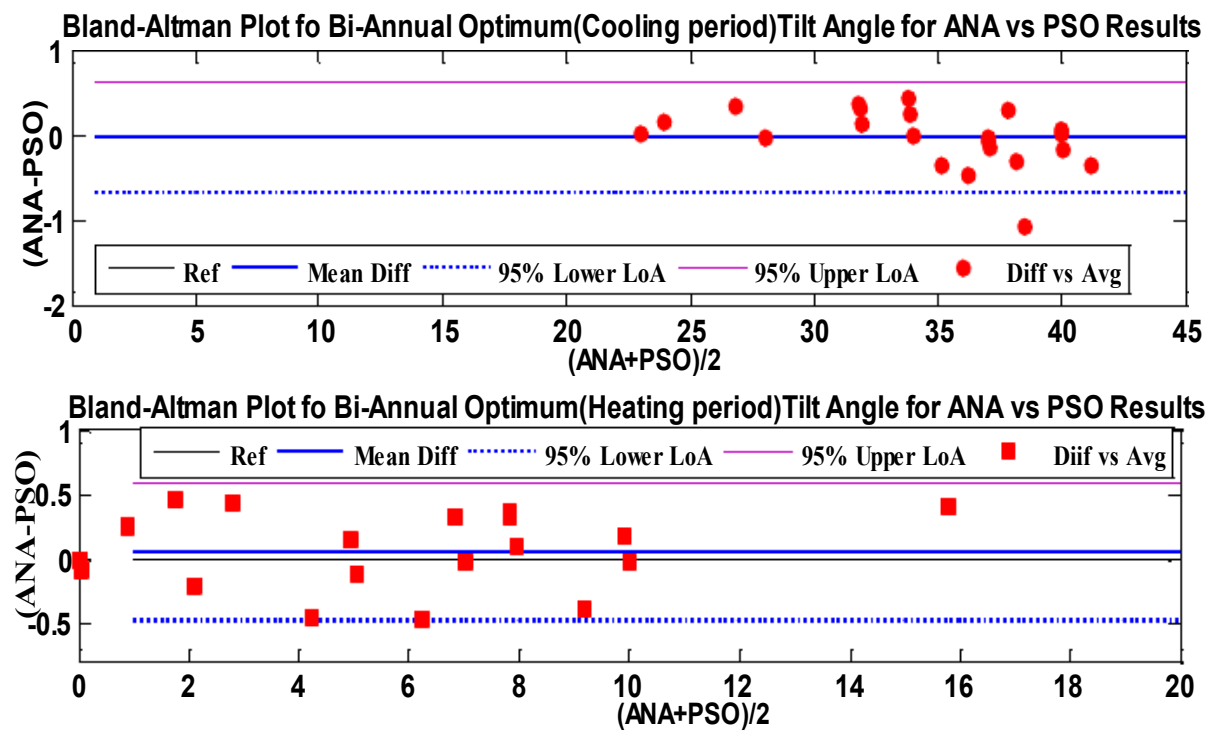

Figure 9 Bland-Altman Plot of Bi-Annual Optimum Tilt Angle of ANA versus PSO Estimator Results

\section{CONCLUSION}

In this study, evolutionary optimization approach such as PSO estimator that maximizes the total solar irradiance $E_{g s m a x}$ on the surface of PV panel has been proposed. The PSO estimator is a model driven approach hence the selection of appropriate model input becomes extremely important. Therefore, the cost function to be optimized using PSO and its constraints are also presented in this work. The PSO estimator predicts the $\beta_{\text {opt }}$ off-line and these results can be used to enhance the energy collection of solar collectors. From the analysis it can be concluded that the PSO estimator is a model driven approach to predict optimum tilt angler $\left(\beta_{\text {opt }}\right)$. This scheme is more effective than data driven approaches such Neural Network, if the target data for training are vague, missing not available. For estimation of seasonal optimum tilt angle, the PSO estimator is more effective, accurate and easy to implement. From statistical study it also can be concluded that the PSO estimator results do not differ by some considered critical difference (at 95\% difference of interval), the ANA could be replaced by PSO estimator.


Figure 10 Bland-Altman Plot of Bi-Annual Optimum Tilt Angle of ANA versus PSO Estimator Results 


\section{Nomenclature}

$E_{L}$ Elevation of the site in (meter)

Ego Extraterrestrial solar radiation on horizontal surface for $\mathrm{dn}^{\text {th }}$ day

Egsmax Maximum solar radiation collection by solar collector on tilted surface $\left(\mathrm{MJ} / \mathrm{m}^{2} /\right.$ day $)$

$E_{g} \quad$ Monthly mean daily global solar irradiance $\left(\mathrm{MJ} / \mathrm{m}^{2} /\right.$ day)

$E_{d} \quad$ Monthly mean daily diffuse irradiance on horizontal surface $\left(\mathrm{MJ} / \mathrm{m}^{2} /\right.$ day)

$E_{b} \quad$ Monthly mean daily beam irradiance on horizontal surface ( $\mathrm{MJ} / \mathrm{m}^{2} /$ day)

$S \quad$ Monthly mean Sunshine hour at horizontal surface

$S_{\max } \quad$ Monthly mean maximum possible Sun shine hour per day at horizontal surface

$G_{S C} \quad$ Solar constant $\left(4.921 \mathrm{MJ} / \mathrm{m}^{2} / \mathrm{hr}\right)$

MSE Mean square error

SOLAR COLLECTOR Photovoltaic Array

ANA Analytical Analysis/ method

WN Winter

AT Autumn

$S M \quad$ Summer

SR Spring

HOT Heating period of the year

COL Cooling period of the year

SNL Seasonal tilt adjustment

SD Standard Deviation

CI Confidence Interval

LOA Limit of Agreement

\section{Greek Letters}

$\beta$ Slope or tilt angle of panel surface with respect to the horizontal surface (degree)

$\gamma$ Surface azimuth angle (degree)

$\delta$ Earth declination angle (degree)

$\rho$ Ground reflectance/ albado

$\phi \quad$ Latitude of the site in (degree)

$\omega$ Hour angle (degree)

$\mathfrak{R}_{b} \quad$ Tilt factor for beam radiation

$\mathfrak{R}_{d} \quad$ Tilt factor for diffuse radiation

$\mathfrak{R}_{r} \quad$ Radiation shape factor for surface w.r.t. surrounding ground

$p_{n}^{j}$ Position of $\mathrm{n}^{\text {th }}$ particle at $\mathrm{j}^{\text {th }}$ iteration

$v_{n}^{j}$ Velocity of $\mathrm{n}^{\text {th }}$ particle in $\mathrm{j}^{\text {th }}$ iteration

$C_{1}, C_{2} \quad$ Acceleration or learning factors 
A Model Driven Optimization Approach to Determine Tilt Angle of Solar Collector in India

$r_{1}, r_{2} \quad$ Independent uniform random number, where $0 \leq r_{1,2} \leq 1$

$P_{L B_{n}}^{j} \quad$ Best local solution / position of $\mathrm{n}^{\text {th }}$ until $\mathrm{j}^{\text {th }}$ iteration

$P_{G B_{n}}^{j} \quad$ Best global solution/position of $\mathrm{n}^{\text {th }}$ until $\mathrm{j}^{\text {th }}$ iteration

$\omega^{\max } \quad$ Initial parameter weight

$\omega^{\mathrm{min}} \quad$ Final parameter weight

$I_{\text {ter }}^{\max } \quad$ Maximum iteration count

$I_{\text {ter }}^{\min } \quad$ Minimum iteration count

$I_{\text {ter }}$ Current iteration count

\section{REFERENCE}

[1] M. Jamil Ahemad, G. N. Tiwari, "Solar radiation model- review," IJEE, Vol.1, issue. 30, April 2010 pp.513-532.

[2] Gopinathan K.K., "A general formula for computing the coefficient of correlation connecting global solar radiation to sunshine duration," Solar Energy, 41: 499, 1988.

[3] Sukhatme S. P., Nayak J K, "Solar Energy Principle of Thermal Collection and Storage," Tata McGraw Hill, India, 2008.

[4] Abhishek Agarwal, Vineet Kumar Vashishtha and S.N. Mishra, "Solar Tilt Measurement of Array for Building Application and Error Analysis", International Journal of Renewable Energy Research, Vol.2, No.4, Oct. 2012 pp. 781-789.

[5] Ari Rabl, "Comparison of solar concentrators", Solar Energy 18: 93-111.

[6] Cooper PI, The Absorption of radiation in solar stills", Journal of Solar Energy, Vol.12, 1969 333-346.

[7] Emanuele Calabr, "An Algorithm to Determine the Optimum Tilt Angle of a Solar Panel from Global Horizontal Solar Radiation”, Hindawi Publishing Corporation Journal of Renewable Energy vol. 2013, Article ID 307547.

[8] Huseyin Gunerhan, Arif Hepbali, "Determination of the optimum tilt angle of solar collectors for building," Elsevier, Building and Environment, vol. 42, 2007. pp. 779-783,

[9] Farzad Jafar kazemi, S. Ali Saadabadi, "optimum tilt angle and orientation of solar surface in Abu Dhabi, UAE", Elsevier, Renewable Energy XXX, 2012 pp. 1-6.

[10] Hamid Moghadam, Farshad Farshchi Tabrizi and Ashkan Zolaghari Sharak, "optimization of solar collector inclination”, Elsevier, Desalination, 265 (2011), pp.107-111.

[11] Murat Kacira, Mehemt Smsek, Yunus Babur, Sedat Demirkol, "Determining optimum tilt angle and orientation of photovoltaic panel in sanliurfra, Yurkey," Elsevier, Renewable Energy 29, 2004.pp. 1265-1275,

[12] Abir Chatterjee, Ali Keyhani, "Neural Network Estimator of Micro grid Maximum Solar Power", IEEE Tran. On Smart Grid, Vol.3, No.4, Dec.2012.

[13] Mubiru J., E. J. K.B. Banda, "Estimation of monthly average daily global solar irradiation using artificial neural networks", Science-Direct Journal of Solar Energy, vol.82 (2008), pp.181187,

[14] James Mubiru, "Using Artificial Neural Networks to Predict Direct Solar Irradiation", Hindawi Journal of Advances in Artificial Neural Systems, Vol. 2011, Article ID 142054, , Aug 2011 pp. $1-7$.

[15] Dixit T. V., Anamika Yadav, S. Gupta, "Optimization of PV Array Inclination in India using ANN Estimator: Method Comparison Study" Sadhana Journal 07/2015; DOI: 10.1007/s12046015-0386-2. 
[16] Mahdi M.El-Arini, Ahmed M. Othman, Ahmed Fathy, "A New Optimization Approach for Maximizing the Photovoltaic Panel Power Based on Genetic Algorithm and Lagrange Multiplier Algorithm", JETCIS, Vol.4, N01. Jan 2013, pp.79-90.

[17] Yaow-Ming Chen, Chien-Hsing Lee, and Hsu-Chin Wu, "Calculation of the Optimum Installation Angle for Fixed Solar-Cell Panels Based on the Genetic Algorithm and the Simulated-Annealing Method", IEEE Trans. Energy Conversion, vol. 20, NO. 2, Jun. 2005. pp. 467-473,

[18] Randy L. Haupt and Sue Ellen Haupt, "Particle Genetic Algorithms," Wiley Inter-science, 2004, pp .189-200.

[19] Cheng-Chen Kuo, "Novel Coding Scheme for Practical Economics Dispatch by Modified Particle Swarm Approach", IEEE Tran. Power Systems, Vol.23, No.4, Nov 2008 pp.1825-1835,

[20] Perez R E and Behdinan, "Particle Swarm Approach for Structrual Design Optimization", Jr. Computer and Structure, Vol.85:1579-88, 2007

[21] Altman D.G. and Bland J.M. "Measurement in Medicine: the Analysis of Method Comparison Studies," The Statistician 32 (1983), Institute of Statisticians, 1983. pp. 307-317,

[22] Ajit P Tyagi, "Solar radiation energy over India”, MNRE Indian Metrological Department, New Delhi, 2009.

[23] Hamza Al-Tahaineh and Rebhi Damseh, Exergy Analysis of a Single-Ended Glass Direct Flow Evacuated Tube Solar Collector, International Journal of Advanced Research in Engineering and Technology (IJARET), Volume 4, Issue 7, November-December 2013, pp. 01-09

[24] Sandeep Kumar and Satbir Singh Sehgal, Experimental Performance Analysis on Flat Bed Solar Collector with and without Microchannel Fins, International Journal of Mechanical Engineering and Technology (IJMET), Volume 8, Issue 6, June 2017, pp.740-749.

[25] S. Mathana Krishnan and V. Srinivasan, Modified Solar Collector Annexed with Residential Solar Cooker, International Journal of Mechanical Engineering and Technology (IJMET), Volume 4, Issue 4, July - August (2013), pp. 62-70

[26] K. Barkavi and R. Senthil, Power Management of Thermoelectric Generator in a Parabolic Dish Solar Collector, International Journal of Mechanical Engineering and Technology, 9(6), 2018, pp. 849-855

[27] S. Harish, V. Koushik Padmanabhan, R. Shivram, S. K. Jayant Jaishwin and A. Naren, Recent Advances of Direct Steam Generation Technology Using Concentrated Solar Collectors, International Journal of Mechanical Engineering and Technology (IJMET), 9(9), 2018, pp. 708717.

[28] S. Aravindan, N. Giridharan and B. Amirdesh Sudhan, The Recent Trends in Optimization of Thermal Performance of Parabolic Trough Solar Collector, International Journal of Mechanical Engineering and Technology, 9(5), 2018, pp. 655-661

[29] Nitesh Singh Rajput, Dipesh Dilip Bhai Shukla, Shiv Kumar Sharma and Deep Rajput, Thermal Analysis of Mwcnt/Distilled Water Nanofluid on The Efficiency of Flat Plate Solar Collector, International Journal of Mechanical Engineering and Technology 8(8), 2017, pp. 224-240 